\title{
COSTO DEL CRÉDITO EN EL PERÚ
}

\section{COST OF THE CREDIT IN PERU}

\section{ESTEBAN AVELINo SÁNCHEZ*}

Docente Asociado de la Facultad de Ciencias Contables, UNMSM

[Recepción: Agosto de 2010 / Conformidad: Setiembre de 2010]

\section{RESUMEN}

¿Cuánto cuesta el capital ajeno en el Perú? El presente trabajo, con base en los estudios del BCRP, da una respuesta a esta interrogante. Previamente se define el concepto tasa de interés. A continuación, sucesivamente, se analizan nueve factores macroeconómicos que afectan las tasas de interés; las características del mercado peruano de crédito (diferenciando: mercado bimonetario, menores tasas de interés para créditos ofertados en dólares, tipo de cliente, dispersión de tasas de interés, asimetría de información, tecnologías crediticias, estructura competitiva del mercado de crédito, ejecución de garantías, evolución de mercado y tendencias decrecientes de las tasas de interés), los factores microeconómicos determinantes de las tasas de interés: costo de fondos, riesgo de crédito, costos operativos y utilidad espera$\mathrm{da}$, los cuales determinan las tasas de interés; por último otros conceptos que se adicionan a las tasas de interés para revelar la tasa del costo efectivo del crédito. Por tanto, la tasa efectiva de las operaciones activas es menor que la tasa del costo efectivo del crédito otorgado por empresas del Sistema Financiero peruano.

Palabras clave: Costo del crédito, Costo efectivo del crédito en el Perú, factores macroeconómicos que afectan las tasas de interés, características del mercado peruano de crédito, factores microeconómicos determinantes de las tasas de interés en el Perú, promedios de tasas de interés efectivas anuales.

\begin{abstract}
How much foreign capital in Peru?

This paper, based on studies of BCRP, gives an answer to this question. Before defining the concept of interest rate. Then, in turn, are analyzed nine macroeconomic factors that affect interest rates, the characteristics of the Peruvian market credit (distinguishing: dual currency market, lower interest rates offered for loans in dollars, customer type, interest rate spread, information asymmetry, lending technologies, competitive market structure of credit, performance guarantees, market development and trends of declining interest rates), microeconomic factors determining interest rates, cost of funds, credit risk, costs operational and expected utility, which determine interest rates, and finally other concepts that are added to the interest rate to disclose the rate of effective cost of credit. Therefore, the effective rate of the lending rate is lower than the actual cost of credit from financial companies in Peru.
\end{abstract}

Key words: Cost of credit, cash cost of credit in Peru, macroeconomic factors affecting interest rates, market characteristics Peruvian credit microeconomic factors determining interest rates in Peru, average annual effective interest rates.

* Magíster en Ciencias Contables, UNMSM. Contador Público Colegiado. Docente Investigador de la Facultad de Ciencias Contables, UNMSM. E-mail: avelino_sa@hotmail.com 


\section{INTRODUCCION}

¿Qué es la tasa de interés?

La tasa de interés es definida como la razón geométrica del interés devengado al capital en una unidad de tiempo, generalmente un año. Otras acepciones: la tasa de interés es un precio básico de la economía, es el precio de los recursos financieros ajenos; como los recursos ajenos que se ofrecen y demandan en los mercados de crédito son sumas de dinero, suele decirse también que, la tasa de interés es el costo del dinero prestado. Para el prestatario, la tasa de interés significa costo; para el prestamista o inversionista, la tasa de interés significa rendimiento o beneficio que recibe por permitirle a otro utilizar su dinero.

Generalmente, la tasa de interés no equivale al costo del crédito. En el Perú, el costo del crédito, según sea el tipo de crédito, comprende la tasa de interés reportada al usuario del crédito y uno o más de los conceptos siguientes: portes, seguro desgravamen, comisión de desembolso, comisión de verificación, estudio de títulos, tasación, gastos notariales, gastos registrales, etc.

En este artículo se analizan los factores macroeconómicos y microeconómicos que afectan las tasas de interés, así como las características del mercado de crédito en el Perú. Los factores macroeconómicos ciertamente afectan las tasas de interés y consiguientemente el costo del crédito, se hace una referencia breve de los mismos; algunos como la inflación tienen incidencia directa en las tasas de interés, sin embargo, al fijar las tasas de interés en el Perú no se discriminan.

Seguidamente se analizan ocho características del mercado peruano de crédito: tipo de cliente (diferenciando ocho segmentos: corporativo, mediana empresa, pequeña empresa, consumo alto medio, microempresa y consumo de bajos ingresos e hipotecario), dispersión de las tasas de interés, asimetría de información, tecnologías crediticias, estructura competitiva delmercado de crédito, ejecución de garantías y resolución de conflictos, evolución del mercado y tendencia decreciente de las tasas de interés, aún altas en comparación con las tasas internacionales.

Luego se analizan, en los cuadros 3.1, 3.2 y 3.3, por segmentos los factores microeconómicos determinantes de las tasas de interés del costo del crédito en el Perú, en moneda nacional y extranjera. Finalmente en el cuadro 3.4 se analiza las tasas de interés reportadas y costo efectivo del crédito para tres segmentos: microempresa, consumo e hipotecario.

\section{FACTORES MACROECONÓMICOS QUE AFECTAN LAS TASAS DE INTERÉS}

Los economistas y los expertos en finanzas dicen que las tasas de interés pueden ser afectadas por varios factores macroeconómicos, no necesariamente concurrentes todos ellos al mismo tiempo, entre otros los siguientes:

1. Oportunidades de producción. Si las personas con excedentes de dinero tienen la posibilidad de invertirlo en un negocio, esos excedentes no estarán disponibles en el mercado para prestarlo. Si el dinero disponible es escaso su precio para conseguirlo aumenta.

2. Propensión al consumo actual. Si los ingresos disponibles mayormente se destinan al consumo, el ahorro se reduce, el costo del dinero aumenta.

3. Nivel de inflación. Las expectativas de inflación en el futuro inciden en las tasas de interés. Si la tasa de inflación mantiene una tendencia creciente, las tasas de interés se incrementan. 
4. Devaluación esperada. Si el tipo de cambio mantiene una tendencia alcista, las personas que prestan dinero en moneda local, reducen su oferta para invertirlo en moneda dura; si la oferta de dinero se reduce aumenta su precio: aumenta la tasa de interés. Si el tipo de cambio mantiene una tendencia decreciente puede causar un efecto contrario en la tasa de interés.

5. Política monetaria. $\mathrm{Si}$, para estimular la economía, el BCRP aumenta la oferta de dinero, el efecto inicial será una disminución de las tasas de interés; sin embargo, una oferta de dinero más amplia puede conducir a un incremento en la tasa de inflación esperada y con ello a un aumento de las tasas de interés.

6. Riesgo por el plazo de vencimiento. Consiste en aumentar las tasas de interés sobre los instrumentos financieros a largo plazo, respecto a los de corto plazo. A mayor plazo de vencimiento mayor tasa de interés.

7. Grado de liquidez del instrumento financiero. Los activos financieros tienen distintos grados de liquidez, dependiendo de las características del mercado donde se negocian. Los activos financieros a corto plazo por lo general son más líquidos que los activos financieros a largo plazo. A mayor liquidez del instrumento financiero menor tasa de interés.

8. El riesgo país. La percepción de riesgo país en los mercados internacionales reduce la demanda de los activos financieros nacionales comercializados en esos mercados, los inversionistas extranjeros no invierten en activos financieros nacionales; si disminuye la oferta de dinero de los mercados internacionales la tasa de interés en el mercado local aumenta.

9. Tasas de interés internacionales. Si en otros países las tasas de interés se incre- mentan los capitales golondrinos se van del país, la reducción de la oferta de fondos prestables causa desequilibrio en el mercado local y se incrementa la tasa de interés en moneda nacional.

\section{CARACTERÍSTICAS DEL MERCADO PERUANO DE CRÉDITO}

De acuerdo con los estudios del BCRP -El Costo del Crédito en el Perú, de junio de 2002, y Revisión de la Evolución Reciente, de junio de 2006-, las principales características del mercado peruano de créditos son: bimonetario, menores tasas de interés para créditos en dólares, tipo de cliente, dispersión de las tasas de interés, asimetría de información, tecnologías crediticias, estructura competitiva del mercado de crédito y evolución del mercado.

En el estudio: "El Costo del Crédito en el Perú”, de junio de 2002; se señala, entre otras características: la oferta de préstamos en Nuevos Soles y dólares (mercado de crédito bimonetario) y menores tasas de interés para créditos ofertados en dólares (que en Nuevos Soles). Esas manifestaciones del mercado de crédito local aún continúan hoy día.

En el estudio "El Costo del Crédito en el Perú". Revisión de la Evolución Reciente, de Junio de 2006; se explican las características siguientes:

\section{Tipo de cliente}

Esta característica está referida a la partición del universo de prestatarios en seis segmentos, coincidente con la práctica de gestión bancaria empleada por los bancos para tomar decisiones estratégicas, tácticas y operativas respecto: a) a la asignación de recursos (operativos y administrativos) para la captación, evaluación, selección y seguimiento de clientes crediticios; y, b) a la determinación de la 
tasa de retorno, los márgenes de ganancia y, tasas de interés activas que exigen a su cartera de crédito.

Los seis segmentos diferenciados son:

a) Corporativo. Constituido por empresas domésticas con ventas anuales mayores a US \$ 10 millones, así como filiales de empresas multinacionales. Al tener acceso a los mercados de capitales interno y externo, tienen un alto poder de negociación frente a los bancos.

b) Mediana empresa. Conformado por compañías con ventas anuales entre US \$ 1 y US \$ 10 millones. El poder de negociación de este segmento es variable y depende del acceso que tengan al mercado de capitales doméstico.

c) Pequeña empresa. Integrado por prestatarios con ventas anuales menores de US \$ 1 millón, que usualmente no tienen acceso al mercado de capitales.

d) Micro-finanzas. Este segmento tiene dos componentes: (i) microempresas, que son personas naturales o jurídicas con un endeudamiento con el sistema financiero menor a US $\$ 30000$ o su equivalente en soles y demandan crédito para financiar actividades productivas, comerciales o de prestación de servicios; y (ii) personas de bajos ingresos que demandan crédito de consumo.

e) Crédito de consumo. Personas naturales de estratos de ingresos: alto y medio, que demandan créditos para atender el pago de bienes, servicios de uso personal o gastos no relacionados con una actividad empresarial. Incluye a los usuarios de tarjetas de crédito y préstamos personales. f) Préstamos hipotecarios. Personas naturales que demandan crédito amparado en garantía hipotecaria, destinado a financiar la construcción o adquisición de viviendas propias.

Esta clasificación toma como base los tipos de crédito establecidos por la regulación de la SBS, excepto el segmento de micro-finanzas, el que ha sido definido como la unión del sector de microempresas y el sub-segmento de créditos de consumo de bajos ingresos.

2. Dispersión de las tasas de interés

La gran dispersión en las tasas de interés es una característica más saltante del sistema financiero peruano. Por ejemplo; en enero de 2002, en operaciones de crédito en moneda nacional dentro del sector formal, se pactaron tasas desde un mínimo de 3,3\% en el segmento corporativo hasta $99 \%$ en el segmento de microempresas. Si se incluye al sector informal o banca paralela, las tasas de interés excedieron con facilidad a $300 \%$ anual.

\section{Asimetría de información}

La asimetría de información por el lado del prestatario se refiere a su desventaja frente al prestamista (la entidad financiera) sobre las condiciones crediticias (tasas de interés, comisiones, penalidades por incumplimiento, monedas, impacto del cambio en la tasa de interés de mercado, etc.), conduciéndolo a la toma decisiones de endeudamiento ineficientes. La asimetría de información por el lado del prestamista surge del conocimiento parcial que tiene sobre el potencial deudor y sobre el destino final del crédito, el cual limita la efectividad del prestamista para determinar la verdadera capacidad y voluntad de pago del prestatario. Ello motiva a los prestamistas, ante un incremento de las tasas de interés de mercado, a responder racionando sus créditos. 
La transparencia de información en los últimos años ha originado grandes avances sobre la asimetría de información, ya se viene incrementando el número de registros de personas y empresas en las centrales de riesgos: Central de Riesgos Pública de la SBS, CERTICOM e INFOCORP. El crecimiento de las entidades de micro-finanzas, también contribuye a una mayor información, especialmente a aquellos estratos de bajos ingresos.

\section{Tecnologías crediticias}

Las tecnologías crediticias se refieren al conjunto de principios, políticas, metodologías de evaluación crediticia y prácticas aprendidas y desarrolladas por una entidad para realizar operaciones en un determinado segmento de mercado.

En términos generales, se puede identificar dos tipos de tecnologías crediticias en el mercado peruano de crédito: una tecnología tradicional y otra de microfinanzas.

a) La tecnología tradicional utiliza información cualitativa y cuantitativa respecto del potencial prestatario o proyecto. Por lo general, dicha información se obtiene de las centrales de riesgos, pero también de otras fuentes privadas y estatales. Esta tecnología ha sido tradicionalmente utilizada por la banca, con el objetivo de atender a empresas medianas y grandes así como a personas con ingresos medios/altos debido tanto a la disponibilidad de fuentes de información como a las mayores escalas en los préstamos. Este tipo de tecnología considera a las garantías reales un mecanismo de reducción de pérdida, razón por la cual es un requisito casi indispensable para el otorgamiento del préstamo. b) La tecnología de micro-finanzas busca enfrentar las asimetrías de información (selección adversa y riesgo) principalmente a través de la generación de información (in situ) sobre sus potenciales prestatarios (micro y pequeñas empresas así como personas de bajos ingresos), quienes usualmente carecen de historial crediticio. El levantamiento de información es realizada por los oficiales de crédito, a través de visitas al negocio, circunstancias en las cuales estiman el flujo de fondos disponible, la solvencia del negocio, la calidad de gestión así como algunos elementos subjetivos vinculados al prestatario (valores morales, referencias, reputación, etc.).

Una característica particular de la tecnología de micro-finanzas es la gestión del crédito (desde la evaluación del prestatario hasta la recuperación del préstamo) realizada por un solo oficial de crédito, quien se encarga de administrar una numerosa cartera de clientes. Otras características adicionales son: la evaluación rápida y generación de vínculos con los clientes, irrelevancia de las garantías reales, entre otras.

5. Estructura competitiva del mercado de crédito

El mercado de crédito, visto desde la segmentación antes definida, presenta estructuras competitivas diferenciadas en su interior. Las alternativas de financiamiento que posee cada segmento así como los márgenes de ganancias que obtienen las entidades crediticias sugieren que las entidades de micro-finanzas gozan de cierto poder de mercado, mientras que la banca múltiple, por el contrario, posee características de competencia perfecta, dicen los estudios del BCRP. 


\section{Ejecución de garantías y resolución de conflictos}

Los procesos de ejecución de garantías en el Perú realizados por vía judicial son costosos, lentos, poco transparentes y de resultados inciertos. Estos factores hacen que las garantías no cumplan su rol y que las operaciones crediticias involucren un mayor riesgo de crédito implícito, lo que resulta finalmente en una mayor tasa de interés.

Según un estudio realizado en el año 2002 por la SBS, un proceso de ejecución de garantías por la vía judicial duraba entre 18 meses y 3 años. El tiempo incurrido en el caso de créditos superiores a S/. 20000 era de 31 meses. La lentitud del proceso así como la pérdida de valor de la garantía (por obsolescencia, uso o depreciación) generaban costos innecesarios a la entidad crediticia. El estudio estimó que una reducción del proceso de ejecución de garantías a 6 meses podría reducir las tasas activas en 2,2 puntos porcentuales.

\section{Evolución del mercado}

En la década del noventa del siglo XX, el crédito del sistema bancario peruano al sector privado mostró un crecimiento sostenido, como porcentaje del PBI pasó de $3,3 \%$ en 1990 al $27,9 \%$ en 1999 . Sin embargo, a partir del año 2000, el sistema bancario tuvo que enfrentar dos cambios importantes que han causado la disminución del financiamiento bancario al sector privado hasta representar el $17,8 \%$ del PBI en diciembre de 2005.

La crisis financiera internacional, puso en evidencia ciertos problemas de gestión de riesgos al interior del sistema y llevó a la banca a restringir sus créditos. De otro lado, el crecimiento del mercado de capitales, impulsado por el Estado a través de la emisión de bonos en soles en el marco del programa "Creadores de Mercado", representó una fuerte competencia directa al sistema bancario, especialmente a las empresas bancarias orientadas al segmento corporativo

\section{Tendencia decreciente de las tasas}

En el año 1990 la hiperinflación en el Perú superó $12000 \%$ anual y las tasas de interés activas de mercado en moneda nacional (establecidas por decreto supremo) anualizadas más de $4000 \%$ anual. De abril de 1991 a la fecha los valores de las tasas interés, activas y pasivas, revelan una tendencia decreciente, como se aprecia en los cuadros siguientes:

Cuadro 2.1. Tasas de interés efectivas anuales promedio de mercado (porcentajes).

\begin{tabular}{|c|c|c|c|c|c|}
\hline \multirow{2}{*}{$\begin{array}{l}\text { JUNIO DE } \\
\text { CADA AÑO }\end{array}$} & \multicolumn{2}{|c|}{ MONEDA NACIONAL } & \multicolumn{2}{|c|}{ MONEDA EXTRANJERA } & \multirow{2}{*}{$\begin{array}{l}\text { JUNIO DE } \\
\text { CADA AÑO }\end{array}$} \\
\hline & Activa & Pasiva & Activa & Pasiva & \\
\hline 1991 & 704,8 & 77,7 & 20,1 & 8,6 & 1991 \\
\hline 1992 & 147,4 & 23,0 & 19,2 & 6,3 & 1992 \\
\hline 1993 & 87,5 & 16,9 & 15,6 & 5,5 & 1993 \\
\hline 1994 & 52,0 & 10,0 & 15,3 & 4,8 & 1994 \\
\hline 1995 & 36,9 & 10,1 & 16,4 & 6,0 & 1995 \\
\hline 2000 & 30,5 & 9,7 & 13,8 & 4,7 & 2000 \\
\hline 2005 & 26,0 & 2,6 & 9,9 & 1,5 & 2005 \\
\hline 2010 & 19,2 & 1,3 & 7,9 & 0,7 & 2010 \\
\hline
\end{tabular}

Fuente: Portal electrónico del BCRP y Notas semanales del mismo Banco. Elaboración: Esteban Marino Avelino Sánchez. 
Cuadro 2.2. Tasas de interés efectivas anuales promedio por tipo de crédito $\left(^{*}\right)$

(Porcentajes)

\begin{tabular}{|l|c|c|c|c|}
\hline & COMERCIAL & MICROEMPRESA & CONSUMO & HIPOTECARIO \\
\hline Moneda nacional & $7.58 \%$ & $32.50 \%$ & $41.99 \%$ & $9.68 \%$ \\
\hline Moneda extranjera & $6.06 \%$ & $20.88 \%$ & $20.81 \%$ & $8.71 \%$ \\
\hline
\end{tabular}

$\left({ }^{*}\right)$ De operaciones activas realizadas en los últimos 30 días hábiles al 15/07/2010

Fuente: Portal electrónico de la SBS

Cuadro 2.3. Tasas de interés efectivas anuales promedio por tipo de crédito en $\mathrm{MN}\left({ }^{*}\right)$

(Porcentajes)

\begin{tabular}{|l|c|c|c|c|c|}
\hline \multirow{2}{*}{ BANCO } & \multicolumn{2}{|c|}{ CRÉDITOS COMERCIALES } & \multicolumn{2}{c|}{ CRÉDITOS MICROEMPRESA } \\
\cline { 2 - 6 } & Descuentos & $\begin{array}{c}\text { A plazo: } \\
181-360 \text { días }\end{array}$ & $\begin{array}{c}\text { Tarjetas de } \\
\text { crédito }\end{array}$ & Descuentos & $\begin{array}{c}\text { A plazo: } \\
\text { hasta } 360\end{array}$ \\
\hline Continental & 13.45 & 12.47 & 37.74 & 32.00 & 20.57 \\
\hline Comercio & 12.72 & 11.83 & 24.02 & 18.12 & 34.28 \\
\hline Crédito & 6.45 & 3.60 & 30.23 & 8.90 & 24.51 \\
\hline Financiero & 9.13 & 25.01 & - & 12.55 & 45.59 \\
\hline Azteca del Perú & - & - & 183.99 & 183.99 & 155.22 \\
\hline Promedio sistema & 7.55 & 8.95 & 30.44 & 13.86 & 36.87 \\
\hline
\end{tabular}

(*) De operaciones activas realizadas en los últimos 30 días hábiles al 15/07/2010

Fuente: Portal electrónico de la SBS

En los cuadros precedentes se observa una reducción sostenida de las tasas de interés promedio. Sin embargo, comparadas con la tasas de inflación (de los últimos 15 años, generalmente, por debajo del $5 \%$ anual) y las tasas de interés internacionales (generalmente, por debajo del $5 \%$ ); pese a su tendencia decreciente continúan aún altas. Todavía algunas entidades crediticias cobran tasas de interés anual superiores al $100 \%$, como puede observar en el cuadro 2.3 precedente y en las páginas de la SBS y de las diversas entidades crediticias que integran el sistema financiero peruano.

\section{FACTORES MICROECONÓMICOS DETERMINANTES DEL COSTO DEL CRÉDITO EN EL PERÚ}

Los estudios del BCRP mencionados señalan como factores microeconómicos determinantes de las tasas de interés los siguientes: el costo de fondos, los costos operativos, el riesgo de crédito, las características de la demanda y la ganancia esperada, como se aprecia en los cuadros siguientes: 
Cuadro 3.1. Segmentos y costo del crédito en Nuevos Soles: Junio de 2004 (porcentajes).

\begin{tabular}{|l|c|c|c|c|c|}
\hline \multicolumn{1}{|c|}{ SEGMENTO } & $\begin{array}{c}\text { TASA DE } \\
\text { INTERÉS }\end{array}$ & $\begin{array}{c}\text { COSTO } \\
\text { FONDOS }\end{array}$ & $\begin{array}{c}\text { RIESGO DE } \\
\text { CRÉDITO }\end{array}$ & $\begin{array}{c}\text { COSTOS } \\
\text { OPERATIVOS }\end{array}$ & UTILIDAD \\
\hline Corporativo & 5,3 & 2,0 & 0,8 & 0,9 & 1,6 \\
\hline Mediana empresa & 11,8 & 2,0 & 3,3 & 2,7 & 3,8 \\
\hline Pequeña empresa & 28,1 & 1,9 & 9,9 & 9,9 & 6,4 \\
\hline Consumo alto-medio & 33,7 & 2,2 & 5,0 & 15,1 & 11,4 \\
\hline Micro-finanzas & 49,8 & 5,9 & 6,8 & 20,3 & 16,8 \\
\hline . Micro-empresa & 51,2 & 5,0 & 6,6 & 19,3 & 20,3 \\
\hline . Consumo bajo & 46,3 & 8,4 & 7,2 & 22,8 & 7,9 \\
\hline Hipotecario & 13,9 & 4,9 & 1,4 & 2,0 & 5,6 \\
\hline
\end{tabular}

Fuente: El costo del crédito en el Perú - Revisión de la evolución reciente. Junio de 2006.

Cuadro 3.2. Segmentos y costo del crédito en dólares USA: Junio de 2004 (porcentajes).

\begin{tabular}{|l|c|c|c|c|c|}
\hline \multicolumn{1}{|c|}{ SEGMENTO } & $\begin{array}{c}\text { TASA DE } \\
\text { INTERÉS }\end{array}$ & $\begin{array}{c}\text { COSTO } \\
\text { FONDOS }\end{array}$ & $\begin{array}{c}\text { RIESGO DE } \\
\text { CRÉDITO }\end{array}$ & $\begin{array}{c}\text { COSTOS } \\
\text { OPERATIVOS }\end{array}$ & UTILIDAD \\
\hline Corporativo & 4,5 & 1,2 & 0,9 & 1,0 & 1,4 \\
\hline Mediana empresa & 7,8 & 1,2 & 3,5 & 2,4 & 0,7 \\
\hline Pequeña empresa & 14,1 & 1,3 & 9,9 & 10,4 & $-7,5$ \\
\hline Consumo alto-medio & 17,3 & 1,2 & 4,4 & 10,7 & 1,0 \\
\hline Micro-finanzas & 26,9 & 4,2 & 5,8 & 19,5 & $-2,6$ \\
\hline . Micro-empresa & 27,0 & 4,1 & 5,7 & 19,2 & $-2,0$ \\
\hline . Consumo bajo & 24,8 & 4,9 & 6,1 & 22,0 & $-8,2$ \\
\hline Hipotecario & 10,7 & 1,2 & 2,2 & 0,9 & 6,4 \\
\hline
\end{tabular}

Fuente: El costo del crédito en el Perú - Revisión de la evolución reciente. Junio de 2006.

La tasa de interés, en cada cuadro, se determina por la suma de los costos de fondos, costos operativos, riesgo de crédito y utilidad (ganancia esperada). En el cuadro 3.2, de costo del crédito en dólares, para los segmentos: pequeña empresa, microempresa y consumo de bajos ingresos, se observa una utilidad (porcentual) negativa de las empresas crediticias. Es decir, el crédito en dólares a estos segmentos estaría siendo subvenciona- do por las empresas crediticias con parte de las utilidades obtenidas en otros segmentos. Claro, la metodología utilizada por las empresas del sistema financiero peruano para la asignación de tasas por segmentos puede ser discutible.

\section{Tasa de interés}

Los aspectos más relevantes para determinar la tasa de interés activa que cobran los oferentes de crédito son: el segmento 
objetivo de mayor importancia y el riesgo de crédito, los ingresos proyectados por segmento (los que dependen de las condiciones del mercado y del acceso al crédito de sus clientes), el criterio costobeneficio en la asignación del crédito por segmento (la entidad financiera imputa a los créditos otorgados los costos de evaluación de todas las solicitudes analizadas: aprobadas y rechazadas. Este aspecto tiene mayor relevancia en las entidades de micro-finanzas, en donde el costo de evaluación, que ya es elevado, tiende a incrementarse por el rechazo de aproximadamente la mitad de las solicitudes analizadas).

Los bancos determinan la tasa de interés de manera diaria. El área de tesorería distribuye a las áreas de negocio las "tasas de transferencia" por moneda y plazo, las que incluyen el costo marginal de fondos y el objetivo de ganancia por segmento. Luego, las áreas de negocios incorporan un margen que cubra los costos operativos y la prima por riesgo de crédito, la misma que se estima sobre la base de la probabilidad de incumplimiento del prestatario. Esta última información normalmente es revisada por el área de riesgos.

En cada segmento, a su vez, existe una gran dispersión de tasas, debido esencialmente a las características específicas de cada operación (destino del préstamo, riesgo del proyecto y del deudor, garantías, plazos, montos, etc.). Los valores mostrados se aplican únicamente para deudores conocidos del sistema bancario, aquellos que ya cuentan con historia crediticia. Los nuevos prestatarios -aquellos sin historia crediticia- se enfrentarán probablemente tasas de interés mayores, ya que para dichos prestatarios, los factores "riesgo de crédito" y "costos operativos" tienden a ser superiores debido al desconocimiento del cliente y a los gastos incurridos en la evaluación del riesgo de crédito.

\section{Costo de fondos}

El costo de fondos está formado por el promedio ponderado de la tasa de interés pagada por las distintas fuentes de fondeo. Comprende el costo ponderado de los recursos utilizados por los bancos, en los que consideran la captación de depósitos, adeudos y emisión de instrumentos de deuda.

\section{Costos operativos}

Resultan de la diferencia entre gastos operativos totales e ingresos no financieros (las comisiones que se cobran por las operaciones no crediticias). Esta forma de considerar los gastos operativos refleja el proceso en que se encuentran los bancos de asignar directamente los costos a las actividades que los generan.

\section{Ganancia esperada}

La ganancia esperada, medida como proporción del capital de la entidad crediticia, se refiere al costo de oportunidad del capital (COK). El nivel que se consigna es el promedio que los bancos desearían obtener por sus operaciones crediticias en cada segmento. Estas metas de rentabilidad corresponden a los objetivos de largo plazo impuesto por los accionistas de los bancos consultados. La ganancia esperada sufrirá modificaciones en su nivel como consecuencia de ofertas y demandas resultantes de un mercado en competencia.

Una vez definida la ganancia esperada más los costos a cubrir, el banco deduce los ingresos que proyecta percibir por comisiones, y determina el nivel de ingresos financieros que exigirá a su cartera 
de colocaciones. Con este nivel de ingresos y con el volumen óptimo de fondos a colocar determina la tasa de interés a cobrar. Los bancos proyectan estos resultados sobre la base de los segmentos en que operan y de su posicionamiento en cada uno de ellos, lo que resulta en el establecimiento de sus objetivos de ganancia por segmento.

\section{Riesgo de crédito}

También conocido como riesgo de incumplimiento, consiste en la probabilidad que un préstamo no sea reembolsado, tal como se prometió. Mientras mayor sea el riesgo, más alta será la tasa de interés. El riesgo de crédito, se expresa como una prima de riesgo.

Para determinar la prima por riesgo de crédito se solicitó a los funcionarios de 5 bancos de una muestra representativa su percepción de este riesgo para un cliente representativo de cada segmento. Esta prima es calculada sobre la base de la experiencia de sus funcionarios, la que es cargada a la tasa de interés cobrada.

Cuadro 3.3. Percepción de riesgo crediticio - muestra de 5 bancos - junio 2004 (porcentajes de cartera de colocaciones).

\begin{tabular}{|l|c|c|}
\hline & $\begin{array}{c}\text { NUEVOS } \\
\text { SOLES }\end{array}$ & DÓLARES \\
\hline Corporativo & 0,9 & 0,9 \\
\hline Mediana empresa & 3,3 & 3,5 \\
\hline Pequeña empresa & 9,9 & 9,9 \\
\hline Consumo alto-medio & 5,0 & 4,4 \\
\hline Consumo bajo & 7,2 & 6,1 \\
\hline Microempresa & 6,6 & 5,7 \\
\hline Hipotecario & 1,4 & 2,2 \\
\hline
\end{tabular}

Fuente: El costo del crédito en el Perú - Revisión de la evolución reciente. Junio de 2006.
Respecto a los préstamos hipotecarios, cabe destacar del cuadro 3 que, pese a su elevada dolarización ( $96 \%$ a diciembre de 2005), la percepción del riesgo de crédito es reducida. En este caso, el efecto del riesgo crediticio-cambiario estaría siendo mermado por la garantía hipotecaria, la cual ejerce presiones positivas sobre la voluntad de pago los prestatarios. Los jefes de familia usualmente tiendan a priorizar el pago de sus cuotas hipotecarias con el fin de evitar perder su inmueble.

Los componentes del riesgo de crédito son la capacidad y la voluntad de pago del prestatario. El primero se refiere a la capacidad del prestatario para generar recursos, de tal manera que pueda cumplir, en los términos pactados, con la obligación asumida. La voluntad de pago está relacionada con el deseo potencial del prestatario de honrar sus obligaciones, el que depende de muchos elementos como la reputación del deudor, la dación de garantías, la existencia de incentivos legales y morales (como la eficiencia del poder judicial y el respeto de los derechos de propiedad), entre otros.

Por el riesgo de crédito el prestatario es obligado a firmar un pagaré en blanco, el que puede ser llenado con la suma total del préstamo (intereses compensatorios, moratorios, gastos de cobranza, entre otros) en caso de incumplimiento. Asimismo, se exige al menos un aval, quien se compromete a devolver la deuda en el caso de que el prestatario no pueda hacerlo.

Elementos adicionales que explican las diferencia de los costos unitarios. La diferencia sustancial entre los costos fijos unitarios de operaciones crediticias en el sector corporativo y los del segmento de microempresa, es fácil constatar porque 
existen varios elementos adicionales que refuerzan esta estructura diferenciada, los que se superponen al efecto escala. Ellos son los: costos de captación de clientes, costos de evaluación y selección de clientes, costos de seguimiento del crédito y costos de recuperación del crédito.

Igualmente hay que señalar las comisiones, particularmente en los préstamos de consumo y para microempresa donde más afectan, ya que ante montos prestados relativamente reducidos, las comisiones llegan a representar una proporción importante del costo del crédito. Sin embargo, es necesario precisar que el cobro de comisiones por créditos no es una política generalizada en todas las entidades financieras. Muchas de ellas cobran únicamente intereses.

\section{EVOLUCIÓN DE LOS FACTORES DETERMINANTES DEL COSTO DEL CRÉDITO}

Según los estudios del BCRP, en todos los segmentos del mercado de crédito, las tasas de interés activas en moneda nacional disminuyeron entre junio de 2004 y diciembre de 2005, con la excepción de la tasa de interés preferencial corporativa a 90 días. La tasa de interés para los créditos comerciales -compuesto por lo crédito corporativo, mediana empresa y pequeña empresa- disminuyó en 0,9 puntos porcentuales. Esta reducción es una consecuencia de la creciente competencia ejercida por el desarrollo del mercado de capitales.

Costo de fondos. De acuerdo con la muestra representativa de 5 bancos, en ambas monedas se incrementó entre junio 2004 y diciembre 2005, con la excepción del costo en moneda nacional para las entidades especializadas en micro-finanzas.
El mayor costo de fondeo responde a la evolución de uno de sus principales determinantes, las tasas de interés de referencia. De junio de 2004 a diciembre de 2005 se produjo una subida de las tasas de interés de la Federal Reserve Bank de los Estados Unidos (FED) y de los bancos centrales de otros países. De otro lado, el BCRP elevó su tasa de referencia de $2,5 \%$ en junio de 2004 a $3,25 \%$ en diciembre de 2005. Cabe recordar que las decisiones de política monetaria del BCRP se anuncian en términos de una tasa de referencia para la tasa interbancaria, la que se espera que afecte al resto de las tasas del mercado. $\mathrm{Al}$ respecto, estudios econométricos muestran que las tasas de interés de corto plazo son las que responden más rápido a los cambios en las tasas de referencia.

La disminución del costo de fondos de las entidades especializadas en micro-finanzas responde a la dinámica propia del mercado de depósitos de estas empresas. A su vez, refleja la mayor competencia que enfrentan por parte de la banca tradicional que ingresa a este segmento con un costo de fondeo significativamente inferior. Por ello, las entidades especializadas en micro-finanzas habrían disminuido sus tasas de interés pasivas para contrarrestar parcialmente las menores tasas de interés activas.

Costos operativos. Entre junio 2004 y diciembre 2005, el costo operativo de la banca especializada en micro-finanzas disminuyó aproximadamente en 3 puntos porcentuales, la misma que obedeció a un conjunto de factores como el incremento de las escalas de operación -mayor volumen de crédito intermediado- y la mayor productividad -mayores colocaciones por empleado- de la banca. Costo efectivo del crédito en el Perú. Muchos prestatarios, principalmente los pertenecientes a los sectores socioeconómicos de bajos ingresos, tienden a pensar que la tasa 
de interés difundida por los bancos representa el costo total de un préstamo. Sin embargo, la tasa de interés representa sólo un elemento más dentro del abanico de cobros que realizan las entidades financieras.

La publicidad imprecisa e inexacta de tales cobros conlleva a los prestatarios a tomar decisiones ineficientes basadas sólo en la tasa de interés antes que en el costo efectivo del crédito. Este último, en ocasiones, resulta significativamente mayor que la tasa de interés. El Cuadro 3.4 muestra un resumen de las tasas de interés y costos efectivos calculados sobre la base de la información publicada por la SBS y del trabajo de campo. Los costos efectivos equivalen a la tasa interna de retorno (TIR) implícita en el flujo de pagos del préstamo, que considera las cuotas a pagar y el monto efectivamente recibido por el prestatario.

Los valores del cuadro 3.4 destacan la discrepancia entre el costo efectivo y la tasa de interés para los créditos otorgados por el Banco del Trabajo, entidad cuyos cobros de comisiones y seguros (no informada a sus potenciales prestatarios) incrementan sustancialmente su tasa de interés reportada.

Cuadro 3.4. Tasas de interés reportadas y costo efectivo del crédito. Junio 2005.

\begin{tabular}{|l|c|c|c|c|}
\hline MUESTRA & $\begin{array}{c}\text { TIPO DE } \\
\text { CRÉDITO 1/ }\end{array}$ & MONTO & $\begin{array}{c}\text { TASA DE INTERÉS } \\
\text { REPORTADA }\end{array}$ & $\begin{array}{c}\text { COSTO EFECTIVO } \\
\text { DEL CRÉDITO (TIR) }\end{array}$ \\
\hline BCP & MYPE & S/.7000 & $50,0 \%$ & $53,1 \%$ \\
\hline BCP & Consumo & S/.7000 & $37,0 \%$ & $40,6 \%$ \\
\hline Mibanco & MYPE & S .7000 & $55,0 \%$ & $55,7 \%$ \\
\hline B. Trabajo & MYPE & S $/ .7000$ & $42,6 \%$ & $91,5 \%$ \\
\hline B. Trabajo & Consumo & S $/ .7000$ & $51,1 \%$ & $171,4 \%$ \\
\hline BBVA & Hipotecario & US $\$ 40000$ & $12,8 \%$ & $18,0 \%$ \\
\hline Bansud & Hipotecario & US $\$ 40000$ & $10,5 \%$ & $12,1 \%$ \\
\hline
\end{tabular}

1/ Los créditos MYPE y Consumo tienen plazos de hasta un año; los hipotecarios, 15 años. Fuente: Visita a agencias bancarias. Portal de Internet de la SBS.

\section{CONCLUSIONES}

La tasa de interés difundida por los bancos representa sólo un elemento más dentro del abanico de cobros que realizan las entidades financieras.

Los prestatarios del segmento corporativo, debido a las relaciones comerciales que mantienen con las entidades bancarias hace mucho tiempo, que ayuda al conocimiento de su perfil de riesgo, y a mayores escalas en sus operaciones crediticias, abonan las tasas de interés más bajas.

Los prestatarios del segmento de microempresa, debido a sus vínculos comerciales incipientes o inexistentes con las entidades bancarias, que no ayuda al conocimiento de su perfil de riesgo, y reducidas escales en sus operaciones, abonan las tasas de interés más altas.

Del análisis realizado a nivel de segmentos se puede concluir que aún persiste una sobrevaloración del riesgo de crédito asociado a los diversos segmentos. Esta apreciación se deriva principalmente de la falta de información crediticia de los potenciales nuevos clientes, lo que genera restricciones de acceso al crédito de la población en general.

Se percibe una mayor competencia de las entidades crediticias en los segmentos más 
rentables (microempresas y consumo), lo que ha permitido una reducción de las tasas de interés activas. Es necesario fomentar políticas que promuevan una mayor competencia en el mercado y evitar aquellas que tengan un efecto contrario al desarrollo de la misma.

Los costos de transacción explican en gran parte de la dispersión en las tasas de interés entre segmentos, afectando de manera considerable el costo efectivo de los créditos de reducida cuantía. El tamaño de un crédito debe considerarse como una magnitud multidimensional y no simplemente una cifra, por cuanto existen des-economías de escala magnificadas que se derivan de una concatenación de elementos vinculados: número de cuotas de repago, monto de cada cuota, saldo deudor promedio, plazos entre cuotas; todos ellos actúan como amplificadores del efecto escala tradicional e incrementan los costos de transacción asociados, no considerados al evaluar el efecto escala tradicional.

De abril de 1991 a la fecha los valores de las tasas interés, activas y pasivas, revelan una tendencia decreciente. Sin embargo, comparadas con la tasas de inflación de los últimos 15 años, generalmente, por debajo del $5 \%$ anual y las tasas de interés internacionales por debajo del $5 \%$; pese a su tendencia de- creciente continúan aún altas. Todavía algunas entidades crediticias cobran tasas de interés anual superiores al $100 \%$.

Las tecnologías crediticias: tradicional y de micro-finanzas, también requieren ser evaluadas, repensadas y quizá sustituidas parcialmente a fin de asignar tasas de interés equitativas socialmente.

\section{REFERENCIAS BIBLIOGRÁFICAS}

1. BCRP - Subgerencia de Análisis del Sistema Financiero y del Mercado de Capitales: "El Costo del Crédito en el Perú: Revisión de la Evolución Reciente" de junio de 2006, publicado en el Portal electrónico del BCRP.

2. Robert Soto Chávez: Artículo, "El costo del crédito en el Perú”, publicado en el Portal electrónico del BCRP como DT N. ${ }^{\circ}$ 2006-004.

3. BCRP: Tasas de interés por modalidades, publicadas en su Portal electrónico y Notas Semanales del mismo Banco.

4. SBS: Tasas de interés por tipo de crédito, publicadas en su Portal electrónico y Boletines de la banca múltiple y empresas de micro-finanzas. 